\title{
MIDAS
}

Museus e estudos interdisciplinares

$3 \mid 2014$

Varia e dossier temático: "Museos y participación biográfica"

\section{Ocupe o museu (com) memórias de Goiânia: 0 público como construtor de conteúdos}

Occupy museum (with) memories of Goiânia: the public as a builder of content

\section{Manuelina Maria Duarte Cândido e Nei Clara de Lima}

\section{(2) OpenEdition}

\section{Journals}

Edição electrónica

URL: http://journals.openedition.org/midas/505

DOI: $10.4000 /$ midas.505

ISSN: 2182-9543

Editora:

Alice Semedo, Paulo Simões Rodrigues, Pedro Casaleiro, Raquel Henriques da Silva, Ana Carvalho

Refêrencia eletrónica

Manuelina Maria Duarte Cândido e Nei Clara de Lima, « Ocupe o museu (com) memórias de Goiânia: O público como construtor de conteúdos », MIDAS [Online], 3 | 2014, posto online no dia 09 junho 2014, consultado no dia 30 abril 2019. URL : http://journals.openedition.org/midas/505 ; DOI $10.4000 /$ midas.505

Este documento foi criado de forma automática no dia 30 Abril 2019

\section{(i) 8 (2)}

Midas is licensed under a Creative Commons Attribution-NonCommercial-ShareAlike 3.0 International License 


\section{Ocupe o museu (com) memórias de Goiânia: O público como construtor de conteúdos}

Occupy museum (with) memories of Goiânia: the public as a builder of content

Manuelina Maria Duarte Cândido e Nei Clara de Lima

Os museus contemporâneos têm voltado seu olhar para contextos específicos, saindo de uma tradição de grandes panoramas e de representação do outro para a apropriação da noção antropológica de alteridade mínima (Peirano 1999). Também podemos perceber a tendência a uma nova forma de abordagem biográfica, não por um viés da memória do poder, marcado pela representação e biografias das elites, mas pelo fortalecimento do poder das memórias das minorias e pela valorização das subjetividades, segundo o que ensina Chagas (2002). Este debate tem provocado uma mudança na forma como a maioria dos museus brasileiros tem procurado aprofundar sua inserção na sociedade a partir de experimentações como as que analisaremos neste texto, que resultou na exposição Ocupe o Museu (com) Memórias de Goiânia.

\section{A experiência de cocuradoria}

As novas demandas se concretizam, dentro dos museus, no desenvolvimento de ações culturais de grupos reduzidos que procuram participar integralmente dos processos de trabalho museológicos, principalmente porque essas instituições não querem mais ser apenas o espaço de exposições-produto e do discurso técnico, mas ser um lugar onde o processo construído participativamente ocupa o centro das atenções. Com isso, os discursos definitivos, abrangentes, totalizadores vão cedendo espaço às experimentações feitas de discursos-fragmento ${ }^{1}$ com grupos sociais diversos, ao admitir as contradições, as lacunas e incompletudes, assim como as disputas de poder e de espaço de representação vão também sendo explicitadas e colocadas em perspetiva. Neste contexto, "a Investigação Biográfica assume-se como uma proposta de construção de uma narrativa 
museológica direcionada para a inclusão social e para o empoderamento das comunidades» (Leite 2012, 5).

A relevância de propostas desta natureza justifica-se, entre outras razões, pela compreensão de que uma «exposição não tem importância por si só, mas sim pela interação entre o museu (o autor), a exposição propriamente e o público» (Cury 2005, 39). $\mathrm{Na}$ experiência de cocuradoria, a autoria também é compartilhada e o público pode ser deslocado do papel de recetor da mensagem formulada pelo museu, tendo a oportunidade de atuar como sujeito e ter valorizadas, como no caso que analisaremos, as suas narrativas e biografias. Se, como preconiza Meneses (1994, 23), a primeira função de uma exposição está ligada à «alfabetização museológica», uma «capacitação do usuário para dominar a convenção», deve fazer parte das estratégias dos museus desvelar com processos participativos a própria formulação e montagem das exposições, para além de um trabalho de mediação voltado para a fruição da exposição-produto.

Todo o esforço deve ser feito para vencer barreiras entre o público e o museu, que são não somente de ordem física, mas cultural, social, atitudinal, entre outras (Pastor Homs, 2009, 138-139). Segundo Hooper-Greenhill $(1998,96)$, entre as razões para as pessoas não visitarem os museus aparecem, nas pesquisas qualitativas, não somente o argumento da falta de tempo, mas a sensação de que é uma instituição destinada a pessoas mais refinadas, além de serem austeros, proibitivos e sem renovação. Algumas vezes aparecem referências a experiências negativas em visitas anteriores. Portanto, o simples convite para o público vir conhecer o museu e as exposições não parece ser suficiente para romper todas as barreiras. ${ }^{2}$

Este texto pretende relatar e analisar, sob os pontos de vista já apresentados, uma experiência de participação biográfica no Museu Antropológico (MA) da Universidade Federal de Goiás (Goiânia, Centro-Oeste do Brasil), cujo mote foi um convite aos moradores de seu entorno para atuar como construtores de conteúdos no museu. Esta ideia surgiu do desejo de atrair e estabelecer uma interlocução com o chamado nãopúblico do museu, aqueles que não o frequentavam, ainda que morassem perto ou frequentassem o bairro em que o MA está sediado. Não pretendíamos que estas pessoas viessem somente como visitantes, mas que vivenciassem o MA por dentro, pelo menos por algum período de tempo, e contribuíssem para uma proposta que colocasse os de dentro, a equipe do MA, professores de Museologia, em diálogo minimamente simétrico com os de fora: anunciávamos que o MA deveria ser ocupado pela população e acolheríamos o que ela trouxesse para ser mostrado a todos.

Antes de apresentar a experiência da cocuradoria da exposição Ocupe o Museu (com) Memórias de Goiânia, faremos uma breve apresentação e enquadramento histórico do MA. Esta instituição foi criada em junho de 1969 e inaugurada a 5 de setembro de 1970. Desde a sua fundação, o museu é um órgão suplementar da Universidade Federal de Goiás (UFG), vinculado à Pró-Reitoria de Pesquisa e Pós-Graduação (PRPPG). Inscreve-se, portanto, na categoria de museu universitário. 0 museu deveu-se à iniciativa de professores do então Departamento de Antropologia e Sociologia, pertencente ao Instituto de Ciências Humanas e Letras, que deu origem à atual Faculdade de Ciências Sociais. Uma de suas primeiras ações foi a realização de uma incursão no Parque Indígena do Xingu ${ }^{3}$, com o objetivo de, entre outras coisas, adquirir acervo para o novo museu que estava sendo criado.

Desde então o museu passou por diversas sedes e gestões, mantendo sempre uma relação próxima com as populações indígenas, por meio de pesquisas etnográficas de cultura 
material e de educação indígena, inclusive com produção de material didático para escolas indígenas, em contato estreito de pesquisadores com professores dessas escolas.

Mais recentemente, uma equipe de antropólogos ligados ao museu e à Faculdade de Ciências Sociais, com recursos do Instituto do Patrimônio Histórico e Artístico Nacional (IPHAN) e da Fundação de Amparo à Pesquisa do Estado de Goiás (FAPEG), realizou a pesquisa que fundamentou o pedido de registro das bonecas Karajá como património cultural imaterial brasileiro. Trata-se de uma cerâmica artística exclusiva das mulheres Iny, como os indígenas que vivem ao longo do rio Araguaia (região central do Brasil) se autodenominam. $O$ reconhecimento deste património intangível, solicitado pelos próprios grupos indígenas, representou mais um patamar de atuação do MA na preservação do património cultural da região central do Brasil, e da sua colaboração direta com os grupos sociais referenciados no seu acervo.

Estimulados pela dinâmica dos conceitos e das práticas museais na contemporaneidade, os profissionais ligados ao MA têm procurado constantemente romper com os paradigmas tradicionais que orientavam as suas atividades até há bem pouco tempo. Um dos sinais da atualização de suas práticas museais é a exposição de longa duração Lavras e Louvores, inaugurada em 2006. Concebida para romper com as narrativas evolucionistas hegemónicas sobre o Centro-Oeste brasileiro, Lavras e Louvores tem sido reconhecida tanto pelas inovações conceituais e discursivas propostas no seu circuito expositivo quanto pela incorporação de recursos expográficos da atualidade. A exposição foi objeto de uma pesquisa que investigou discursos expositivos sobre povos indígenas em museus antropológicos universitários brasileiros. Entre outras coisas, foi observado que:

O Museu Antropológico da UFG utiliza até mesmo de linguagens da arte contemporânea - as famosas instalações - para se referir ao indígena existente no território nacional, constituindo-se num elemento diferencial em relação às demais narrativas analisadas. É necessário ressaltar também que essa exposição, talvez por ser mais recente que as demais, inova na utilização de recursos expográficos e na abordagem antropológica apresentada (Vasconcellos 2012, 135).

O texto de abertura de Lavras e Louvores afirma: «Que toda região é uma construção cultural ou simbólica à espera de interpretação e não uma realidade externa independente de nós» (Lima e Sena 2006). A exposição é provocativa por escapar a uma narrativa cronológica evolucionista e propor novas perspetivas de análise da relação urbano/rural, passado/presente, trabalho/festa, além de outros estímulos expográficos que contribuem para desconstruir e reconstruir imagens sobre o sertão, sobre as identidades culturais na região central do Brasil e sobre o próprio papel do MA como construtor de narrativas identitárias, enveredando também pela metalinguagem. Portanto, não surpreende que o MA esteja procurando romper com fórmulas tradicionais, realizando ações provocativas ao estimular as comunidades e segmentos da população a usá-lo como instrumento para sua expressão e construção dos seus lugares sociais. A ideia da exposição Ocupe o Museu (com) Memórias de Goiânia inscreve-se como uma dessas ações e, como já foi dito, surgiu em reuniões conjuntas da equipe do MA com o curso de Museologia, para pensar a programação da Semana de Museus ${ }^{4}$ de 2012.

$\mathrm{Na}$ ocasião foram levantadas diversas possibilidades, sobressaindo a proposta de aproximação/interlocução com o chamado não-público, isto é, aqueles que não frequentam o MA ${ }^{5}$. Muitas possibilidades de ação foram apresentadas e definiu-se pela ocupação do MA em vários sentidos, a começar pela elaboração conjunta de uma exposição, na qual a equipe do MA garantisse o apoio técnico e metodológico para a realização de uma proposta cuja conceção fosse construída por pessoas de fora. As 
discussões que se travaram nessa definição das atividades para a Semana de Museus de 2012 encontram eco nas palavras de Moutinho $(1994,7)$ que propõe o deslocamento do papel da exposição nos museus:

Expor é ou deveria ser, trabalhar contra a ignorância, especialmente contra a forma mais refractária da ignorância: a ideia pré-concebida, o preconceito, o estereótipo cultural. Expor é tomar e calcular o risco de desorientar - no sentido etimológico: (perder a orientação), perturbar a harmonia, o evidente, e o consenso, constitutivo do lugar comum (do banal).

A experiência teve início com a realização de abordagens pessoais e entrega de convites impressos a transeuntes e moradores nas proximidades do MA para que participassem de reuniões no museu com o objetivo de trocar ideias e realizar uma eventual exposição. 0 trabalho de campo, tanto nas abordagens aleatórias a pessoas que circulavam pela praça Universitária, onde o MA está sediado, quanto nas visitas às casas de moradores, foi feito pelo grupo constituído da equipe do MA e de professores de Museologia que se dividiu para alcançar moradores de casas e prédios das ruas vizinhas, usuários da praça, vendedores e frequentadores da feira que lá ocorre aos domingos. Entre os que participaram das reuniões estavam estudantes, donas de casa, aposentados, designers, um fotógrafo e um vigilante do MA, que também demonstrou interesse em integrar o projeto (Oliveira 2012).

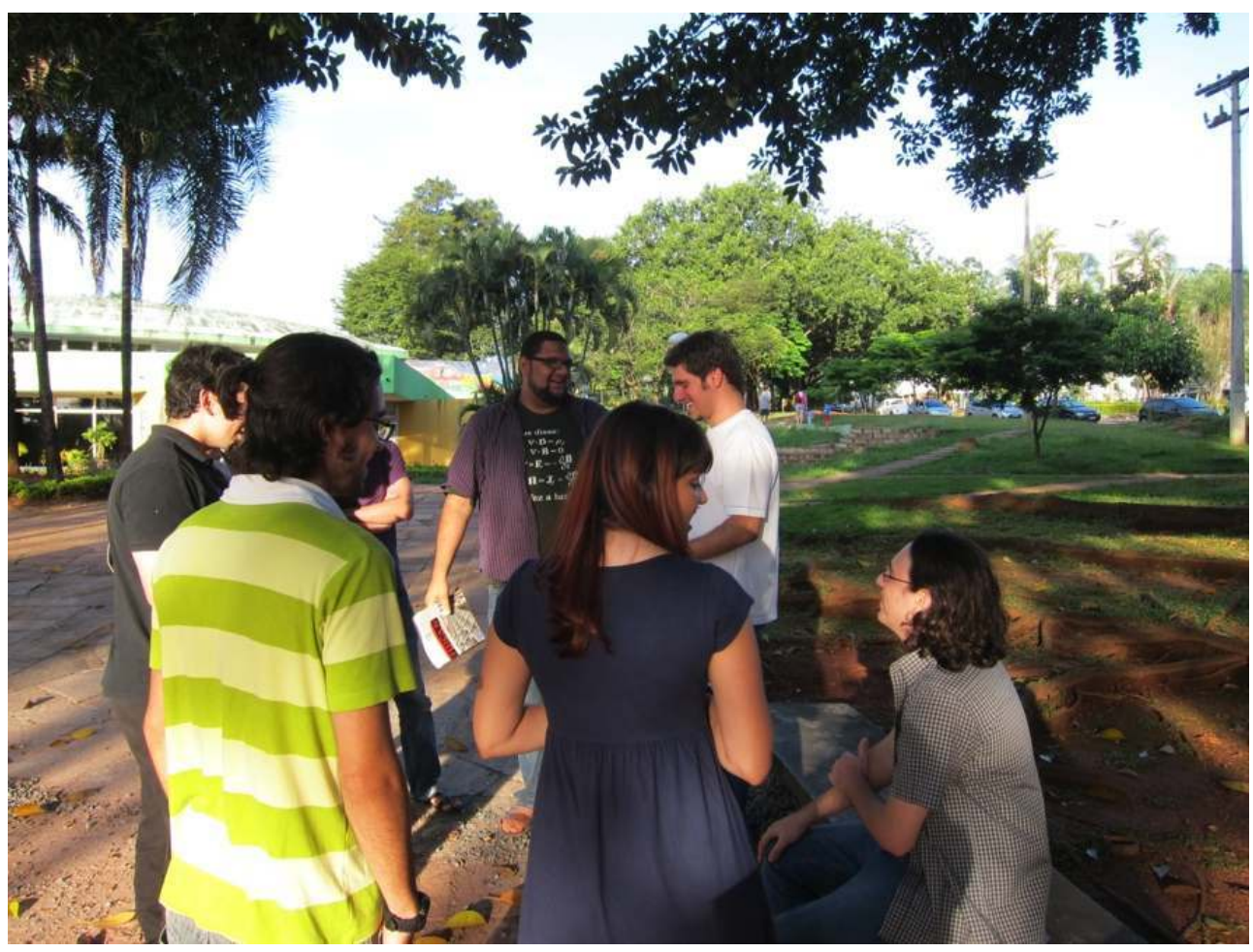

Fig. 1 - Abordagem do não-público na praça Universitária, em frente ao Museu Antropológico. 04/03/2012

Foto de Manuelina Duarte. Acervo do Museu Antropológico

Durante aproximadamente dois meses houve reuniões entre a equipe do MA e do curso de Museologia com essas pessoas, que alternavam as suas presenças nas reuniões, mas não ao ponto de inviabilizar a proposta. Nesses encontros, além da sensibilização com a mostra de um filme ${ }^{6}$, visita guiada à exposição Lavras e Louvores, as pessoas eram estimuladas a apresentar as suas memórias e indicar objetos pessoais e familiares que consideravam ser significativos para uma exposição. 0 exercício de interlocução estava 
voltado para criar situações que promovessem a passagem dessas pessoas da condição de não-público não somente para a de público, mas principalmente para a de protagonistas de uma ação cultural no MA.

De início, a experiência de ocupar o MA pelo não-público trouxe a reflexão sobre as intersubjetividades em Museologia, ou «uma viagem na construção dos processos museológicos», como proposto por Leite:

Nas narrativas museológicas tradicionais, a construção do conhecimento está centrada no museólogo, que legitima a produção do discurso nos objetos socialmente significativos que ilustram e interagem com essa a narrativa legitimando-a. Uma Museologia crítica procurará romper com esta relação viciada entre um sujeito (museólogo) ungido por um saber legitimado (no exterior) e o objeto significativo (revelado pelas relações sociais). Procura romper com as relações centradas na produção de narrativas hegemónicas que se reproduzem a si mesmas, reinventando-se incessantemente a si mesma.

Procura romper esta relação por via da busca do conhecimento do outro, através dele mesmo. Na proposta da intersubjetividade a narrativa museológica é construída pelo outro. Daí a importância da sua palavra e da sua ação na construção do processo museológico. Não é a construção duma ideia criada no seio duma comunidade hegemónica que prevalece, mas sim o processo de construção dessa hegemonia como ação que se constitui como narrativa. $(2012,16)$

O esforço de se deixar conhecer por dentro e procurar conhecer o morador e o transeunte das proximidades do MA instituiu um processo dialógico de troca de experiências e de escuta de memórias que terminou por provocar muitos deslocamentos de nossas velhas (e às vezes, insistentes) conceções sobre a relação do público com o museu, além de colocar em perspetiva o jogo de ocultação que também está presente na seleção do que expor. Enfim, todo o trabalho conjunto resultou num amplo exercício educativo, que mais nos educou do que a eles, sobre as questões da memória e do património.

No decorrer das reuniões, alguns objetos iam sendo trazidos pelo grupo: uma chaleira de ferro, uma máquina de costura, uma garrafa descartável de água mineral, moldes de bordados e fotografias. Alguns deles eram trazidos apenas para serem expostos naquela ação, mas outros foram doados ao MA, como foi o caso da máquina de costura. Junto com os objetos e com as fotografias, muitos relatos de memórias, a maioria delas referidas ao tempo da infância e da adolescência vivido em contato com o córrego Botafogo e as suas imediações, uma região no centro da cidade, os seus lugares de moradia desde então.

As reuniões, por algum tempo, tornaram-se então encontros de rememoração: lembranças e biografias individuais incrustadas nos espaços da cidade de Goiânia iam sendo cruzadas e compartilhadas pelo grupo num exercício profundamente afetivo de se conceber a cidade propiciado pelo MA. Nesses encontros o título original do projeto Ocupe o Museu foi acrescido do seu subtítulo, Memórias de Goiânia. Por sua vez, esse exercício mobilizou de tal forma a equipe que resolvemos ampliar o registro dessas memórias, através de gravações de relatos com alguns moradores que, por qualquer razão, não puderam participar das reuniões no MA. Ao serem editados em formato de um vídeo documentário, ele passou a fazer parte das atividades do Ocupe o Museu e integrou, inclusivamente, o circuito expositivo.

Além do vídeo, esta mobilização desencadeou também na equipe do MA o desejo de realizar uma pesquisa bibliográfica sobre a memória cultural da construção de Goiânia e em livros de poesia, principalmente de autores regionais, cujos temas abordassem a cidade, os seus tempos e rios. Trechos de poemas e de textos foram então selecionados, outras imagens fotográficas da região foram pesquisadas em acervos de outros museus e 
colecionadores da cidade, novas fotografias foram feitas... Junto com os objetos selecionados formaram a matéria da exposição Ocupe o Museu (com) Memórias de Goiânia.

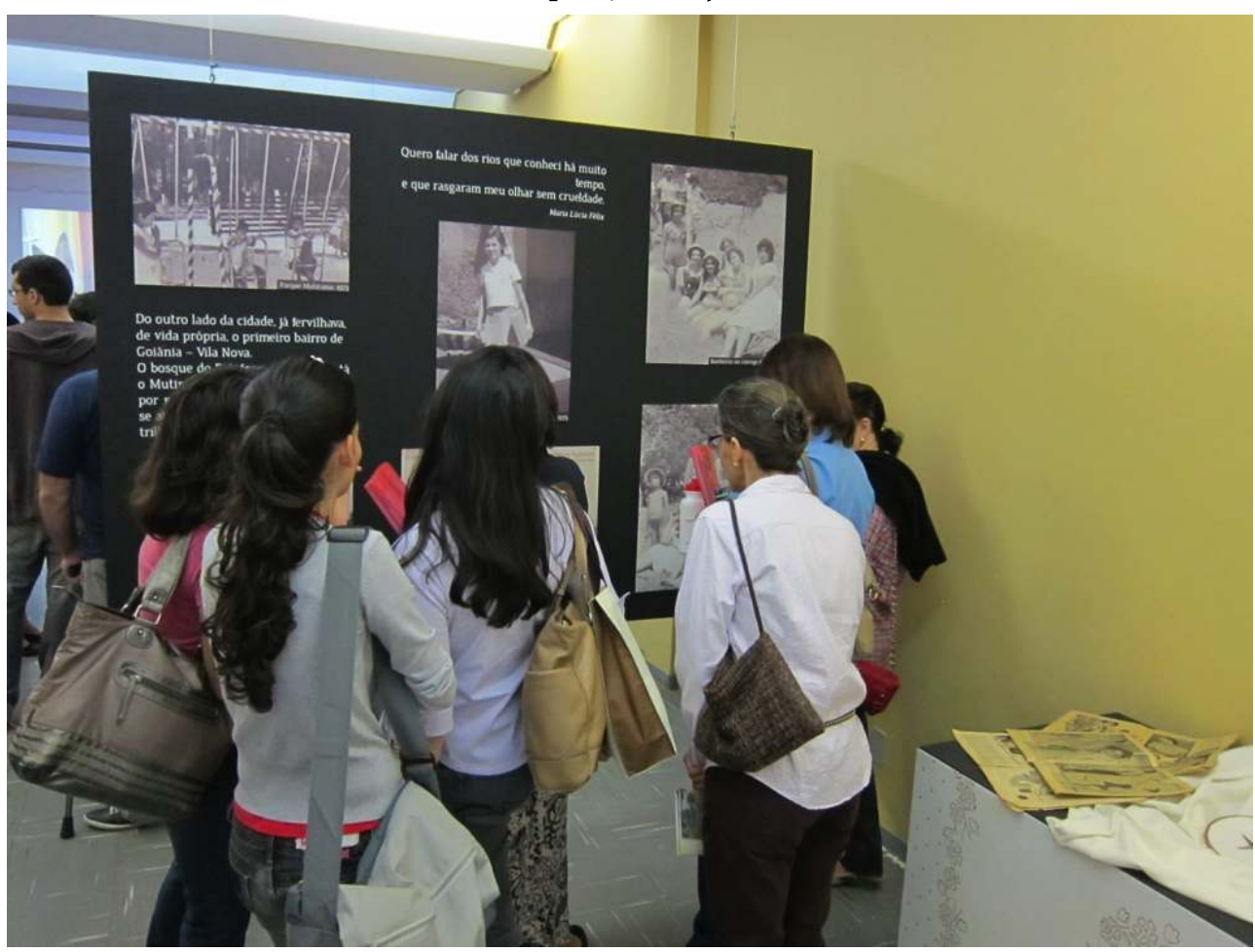

Fig. 2 - Abertura da exposição Ocupe o Museu Memórias de Goiânia, 17/05/2012

Foto de Manuelina Duarte. Acervo do Museu Antropológico

Goiânia é uma cidade planejada, cuja pedra fundamental foi lançada em 1933 e a inauguração ocorreu em 1942. A partir dos anos de 1970 e 1980 a cidade teve um enorme aumento populacional, atingindo um milhão de habitantes na década de 1990. Toda a região metropolitana de Goiânia passou por intensas e rápidas transformações, em consequência das quais se instalaram problemas ligados ao uso do solo, ao transporte urbano, à habitação, à segurança pública, entre outros. Nem todos os museus da cidade estão de facto abertos para refletir sobre estas questões, sequer referem-se a uma história mais contemporânea nas suas práticas de recolha e exposição. 0 trabalho mais direto com a população local, a exemplo dessa experiência de interatividade com o que até então era considerado não-público, também não faz parte das práticas quotidianas da maioria das instituições museológicas da região.

\section{Reflexões sobre a ocupação do Museu Antropológico}

Um breve relato da proposta e das atividades realizadas permite considerar a experiência, ainda que de caráter experimental, como dando início à participação biográfica no MA, além de propiciar uma reflexão sobre estas biografias na história da cidade. Segundo Leite:

Os objetos biográficos transportam a densidade de significados que compõem as diferentes experiências dos sujeitos, as suas expectativas de ação e a natureza relacional onde a interação se processualiza. Esta riqueza pode ser apropriada pelo olhar museológico para construir uma prática de relacionamento entre o individual e o social ou vice-versa, na medida em que para além da sua natureza reflexiva, 
como forma de consciência do real a interação biográfica assume-se como uma prática de integração de dados e com uma prática transformacional. $(2012,23)$

Assim, o papel que o MA assumiu foi o de mediador entre as citadas experiências e as expectativas, entre as diferentes memórias e narrativas, entre o individual e o social, entre o oral e o escrito. Ao invés de propor um discurso único e com pretensões de totalidade, o MA apropriou-se do caráter fragmentário da sua época e da memória dos indivíduos que vivem no seu entorno e colocou-se ao serviço das histórias que aquele grupo pretendia contar, histórias que enlaçavam a vida pessoal com a vida da cidade, a infância e as adolescências de cada um dos participantes com a história da construção da cidade e com os dias atuais. Em diálogo com esta proposta, a elaboração de textos para a exposição aconteceu muito mais por meio da seleção de trechos da literatura que pela produção de textos novos. Assim, outros atores sociais, como estudiosos, poetas e escritores, uns já mortos e outros contemporâneos da cidade narrada pelas memórias do grupo, foram integrados à ação e vieram acrescentar as suas interpretações no processo de dizer e ouvir a polifonia de vozes que a cidade comporta. Existir na contemporaneidade é ser heterogéneo, diverso e fragmentado.

$\mathrm{Na}$ abertura da exposição Ocupe o Museu (com) Memórias de Goiânia, houve um momento emblemático dessas construções narrativas - uma roda de conversa - com todos os atores participantes do processo, logo após terem percorrido o circuito expositivo, juntamente com familiares e amigos, além de outros visitantes. Nesse evento, contavam a si próprios e aos outros participantes como foi o desenrolar do trabalho e mostravam-se orgulhosos por terem construído a exposição. Na ocasião, um dos participantes definiu o museu como «uma coisa útil, instrutiva e social». Esta conceção, dita num contexto profundamente afetivo, lembra a de muitos estudiosos da Museologia que, ao definirem a função dos museus, também se referem ao seu papel preservacionista, educativo e transformador. Por isso, e por todo o processo de interatividade do MA com o que era considerado seu não-público, avaliamos ter cumprido o objetivo do projeto Ocupe o Museu, não só como formação de novos públicos, mas como constituição de novas relações com o museu, potencialidades de experiências mais ricas de intersubjetividades e pedagogias. 


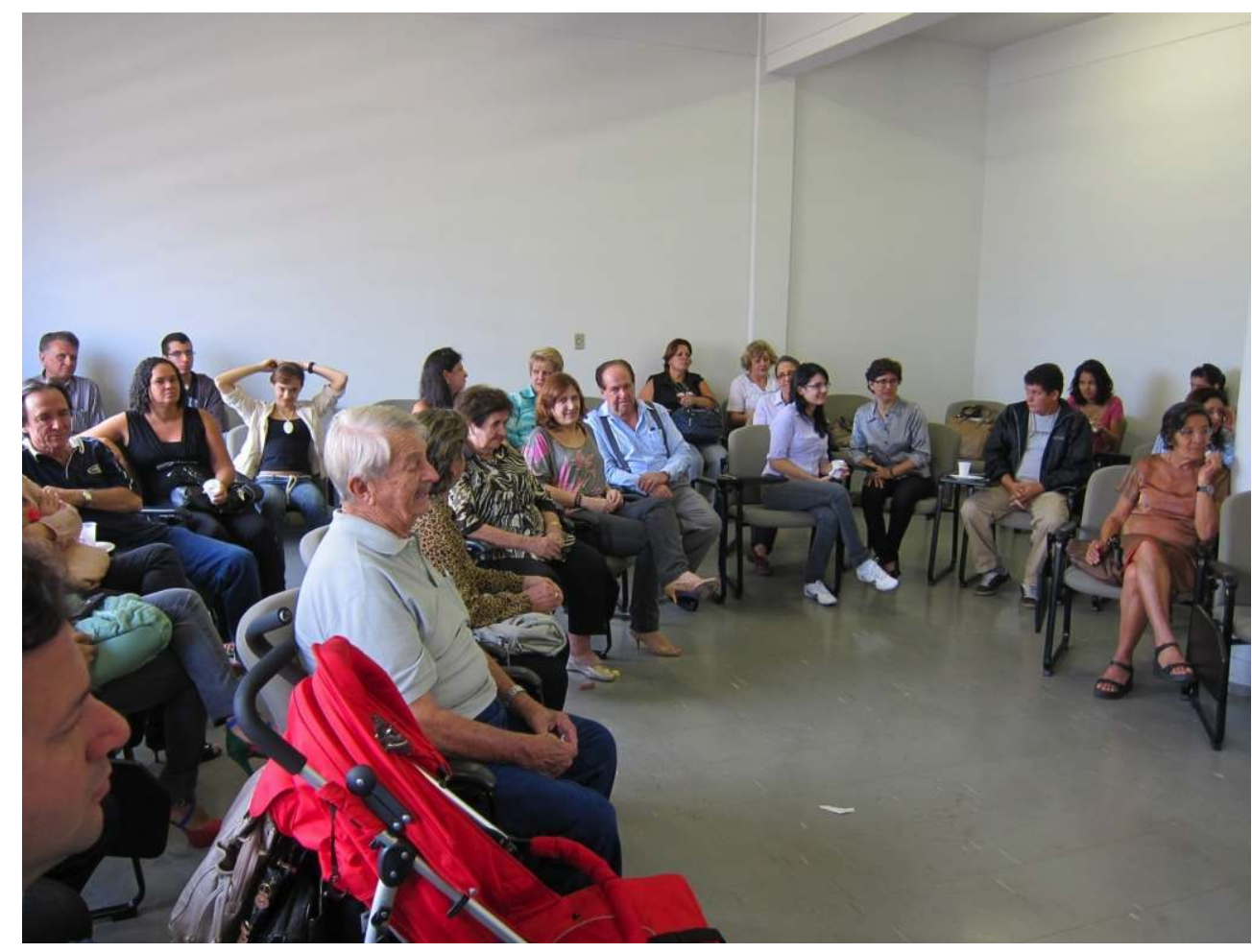

Fig. 3 - Roda de conversa com os moradores do entorno do Museu Antropológico, construtores da exposição Ocupe o Museu Memórias de Goiânia. 17/05/2013

Foto de Manuelina Duarte. Acervo do Museu Antropológico

A exposição permaneceu no MA de 17 de maio a 13 de junho de $2012^{7}$ e um ano depois, na Semana de Museus de 2013, a exposição foi relançada no Museu da Imagem e do Som de Goiás no dia 4 de abril de 2013, quando novas cópias do vídeo foram distribuídas ao público presente, entre eles os participantes da primeira edição, ampliado com muitos outros amigos e familiares.

Pelo que já se foi apresentando quanto às escolhas e abordagens que fundamentaram o projeto Ocupe o Museu, podemos considerá-lo também como uma ação de inclusão social, compreendida de uma maneira mais ampla do que apenas como eliminação de obstáculos (físicos, financeiros, atitudinais) para o acesso aos museus, visando o «desenvolvimento de ações culturais que tenham impacto político, social e econômico, e que podem ter alcance tanto a curto quanto a longo prazo» (Aidar 2002, 60).

Para Leite $(2012,25)$ «o desafio essencial das metodologias biográficas decorre no processo da formação da consciência do individual como parte do social», ou seja, a própria participação num novo papel é transformadora, pois de não-público de museus estas pessoas passaram não apenas a público, mas a sujeitos de um processo de construção do discurso de uma instituição, o que permite uma reflexão sobre o seu lugar de fala e o seu poder de construir as instituições, não só frequentá-las ou ser um usuário passivo.

Como experiência de integração radical do não-público, o projeto Ocupe o Museu, que teve essa exposição como primeira ação, motivou outras iniciativas, concretizadas de diversas formas e ainda abertas a novas propostas de ocupações. Podemos mencionar os seguintes desdobramentos:

1 - A exposição realizada pela Escola Municipal Professora Silene de Andrade por iniciativa de professores de Artes que procuraram o museu para a realização de uma 
exposição de trabalhos realizados pelos estudantes, especialmente com fotografias. Denominada Olhares - A Escola Ocupa o Museu, a exposição foi realizada pela equipe do MA (incluindo estagiários de vários cursos de graduação, como Museologia, Artes Cênicas, Pedagogia, entre outros) em conjunto com representantes da escola. A montagem da exposição também realizou a integração da equipe do MA com alunos do ensino fundamental daquela escola, já que o acervo a ser mostrado era constituído de fotografias e objetos feitos e/ou colecionados por eles no contexto de projetos pedagógicos da escola. O evento de abertura da exposição contou com um expressivo número de atividades de grande impacto junto à comunidade escolar e universitária, ocupando o prédio e os seus jardins com a apresentação de performances, com o contar de histórias, teatro, música e dança, fazendo com que a abertura da exposição se tornasse um grande happening que integrou escolas do ensino fundamental e superior, vários cursos de graduação e a equipe do MA, além de público espontâneo, no decorrer de um dia inteiro. A exposição de fotografias, caleidoscópios, máquinas fotográficas e objetos artesanais produzidos pelos estudantes da Escola Silene de Andrade permaneceu aberta ao público no museu de 7 de maio a 28 de maio de 2013. O seu tema gerador foi um projeto da Escola Silene de Andrade, que associou a questão ambiental e a cidade de Goiânia por meio da fotografia.

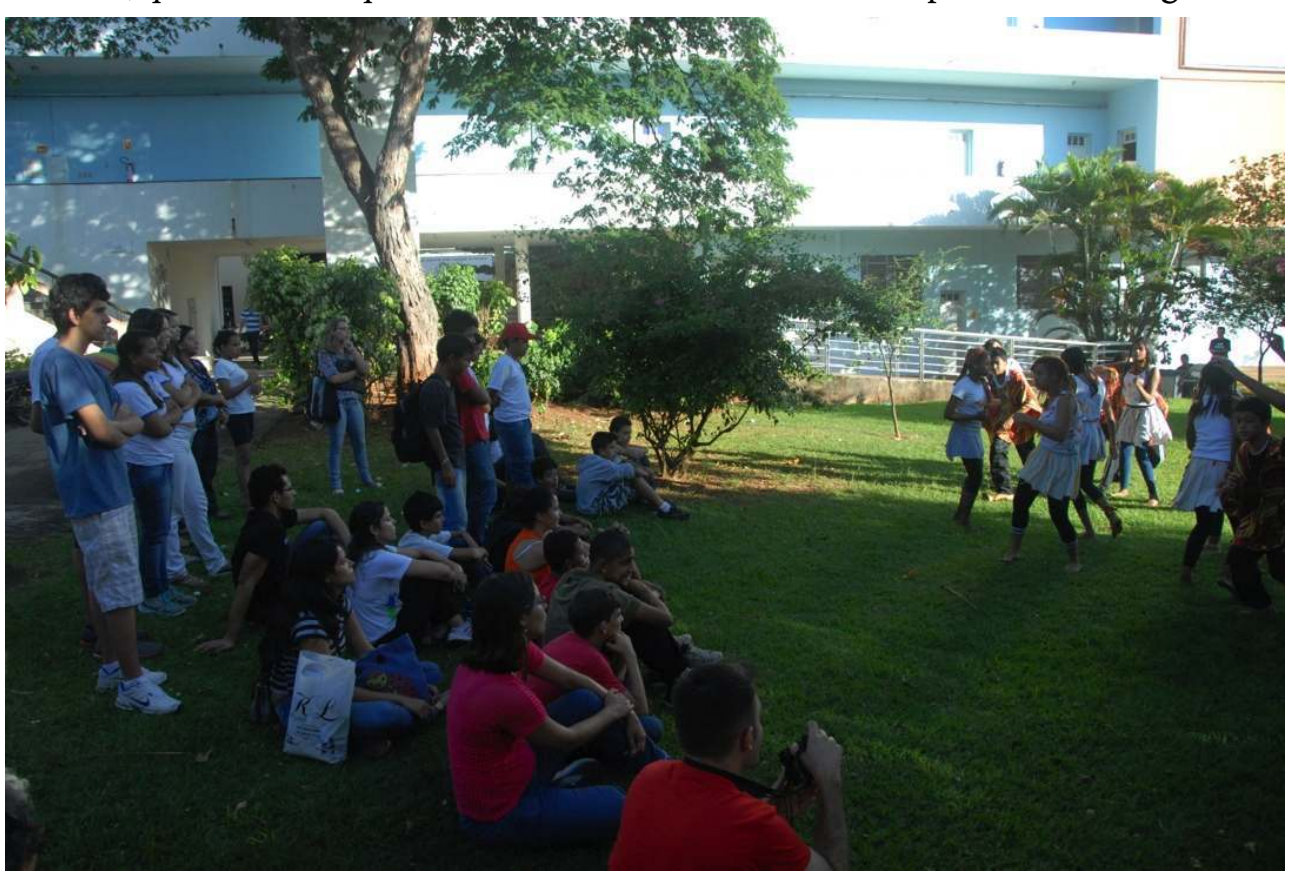

FIg. 4 - PERFORMANCE A TRAVESSIA DO ATLÂNTICO, NOS JARDINS DO MUSEU ANTROPOLÓgICO REALIZADA POR ALUNOS DA ESCOLA MUNICIPAL PROFESSORA SILENE DE ANDRADE, NO DIA DA ABERTURA DA EXPOSIÇÃO OLHARES - A ESCOLA OCUPA O MUSEU. 15/07/2013

FOTO DE JOÃO PAULO FALCÃO

2 - O projeto Ocupe o Museu Também à Noite foi idealizado em parceria com o curso de bacharelado em Museologia da UFG, que tem o MA como seu principal laboratório. Neste caso, em disciplinas práticas ligadas à área da ação educativo-cultural em museus, a professora propôs abrir o MA para a visitação noturna, fora do horário normal de funcionamento, e atender com os alunos da disciplina, o público que, por diversas razões, não pode frequentar museus durante o dia. Para que esse público fosse informado do novo horário de atendimento, houve um trabalho conjunto da professora da disciplina com a equipe da Coordenação de Intercâmbio Cultural do MA, para proceder o agendamento prévio das visitas no período noturno. Desta forma, o MA beneficiou com a 
ampliação do horário de atendimento uma vez por semana e também as escolas ligadas à educação de jovens e adultos ${ }^{8}$, bem como os cursos superiores noturnos de outros centros universitários e faculdades da região, grupos que normalmente demandam estes agendamentos, mas encontram dificuldades de atendimento pelos museus da cidade, a não ser excecionalmente, devido ao fato de a maioria deles não abrir ao público no período noturno. Por outro lado, os alunos de Museologia puderam experimentar uma prática concreta, e não simulada, de atendimento de público, tanto na preparação como realizando a mediação, aprenderam a lidar com cancelamentos e outros imprevistos comuns à dinâmica do contato direto com o público real dos museus.

Além destas experiências mais profundas, o MA tem se constituído sempre como um canal de expressão para aquele que é considerado o seu público mais próximo, os alunos e servidores da UFG, notadamente da Faculdade de Ciências Sociais e do curso de Museologia, recebendo as propostas de maneira sempre acolhedora e buscando viabilizálas, ao possibilitar o financiamento de palestras de especialistas da Museologia e áreas afins, nacionais e estrangeiros, seja ao acolher projetos de exposição, de pesquisas e outras iniciativas que diversifiquem o público e o integrem nas suas atividades. Da mesma forma, na Semana de Museus de 2013, toda a programação foi pensada a partir da iniciativa dos próprios estagiários da instituição.

\section{Museus e participação: Algumas considerações}

O tema da participação em museus está cada vez mais candente e assume parte significativa das páginas de museus como o Museu Histórico de Frankfurt, inclusive com uma proposta semelhante à nossa, na linha Ocuppy Museum ${ }^{9}$. Também foi matéria da conferência anual do COMCOL (Comité Internacional do ICOM para as Coleções), em 2011, realizada em Berlim: Participative Strategies in Documenting the Present. Na sua palestra, Mensch (2011) apontou que há diferentes tipos de participação em museus (front office participation $\mathrm{x}$ back office participation) $\cdot{ }^{10}$ Segundo o autor, é fácil incluir a participação na recolha e na preparação de exposições, mas o que dizer a respeito, indaga, de participação em todos estes procedimentos padrões que ocorrem nos museus e que foram tão fortemente desenvolvidos no nosso campo profissional? Nós realmente aceitamos participação? A cocuradoria deverá alterar estes padrões? ${ }^{11}$ Neste ponto, o autor alinha-se com outros que defendem uma revolução baseada em novos perfis de profissionaisamadores. 0 profissional teria um papel mais próximo de um facilitador, um catalizador de perspetivas, experiências e relações, conforme refere Angela Jannelli (cit. por Mensch 2011).

Mensch, citando Simon (2010), distingue quatro diferentes tipos de relação do público com o museu:

- ideia de audience: público que eventualmente contribui com a instituição;

- colaboradores;

- cocriadores;

- «hospedeiro»: uma forma mais ampla de participação na qual o museu funcionaria como uma plataforma na qual o público agregaria conteúdo produzido por ele mesmo.

Mensch (2011) chama também a atenção para como os profissionais de museus se arvoram como definidores de comunidades e de lideranças comunitárias, sem que necessariamente isto corresponda à perceção de quem faz parte ou é líder da comunidade 
por ela mesma. Por outro lado, o autor ressalta a importância do delineamento de comunidades patrimoniais (heritage community), não como comunidades locais, mas comunidades com interesses comuns, o que pode ser cada vez mais importante diante dos deslocamentos frequentes, desenraizamento e enorme trânsito de informações que marca na contemporaneidade a construção das identidades.

Finalmente, Mensch (2011) aponta um desafio que é a sustentabilidade desse tipo de experiência, em razão de dificuldades na continuidade de projetos com base na participação. É preciso, então, pensar a participação de uma forma comprometida com o futuro das instituições.

Para concluir, lembramos as advertências de Soulier (2013), que na sua tese propôs dar a palavra aos autóctones e questionar a capacidade das exposições dos museus expressarem diferentes pontos de vista. Para esta autora, o museu afirma-se como um lugar de reconhecimento não somente quando promove relações entre visitantes e exposições, mas quando se apresenta também como um espaço de produção. Hoje, é importante que o museu se coloque numa posição de abertura para que a construção de conteúdos e a produção de sentidos sejam propostas pelas comunidades e não somente de dentro para fora.

\section{BIBLIOGRAFIA}

Aidar, Gabriela. 2002. "Museus e Inclusão Social.” Ciências \& Letras (31): 53-62.

Black, Graham. 2005. The Engaging Museum: Developing Museums for Visitor Involvement. London e New York: Routledge.

Canevacci, Massimo. 1993. A Cidade Polifônica: Ensaio sobre a Antropologia da Comunicação Urbana. São Paulo: Studio Nobel.

Chagas, Mário. 2002. "Memória e Poder: Dois Movimentos." Cadernos de Sociomuseologia (19): 4381.

Cury, Marília Xavier. 2005. Exposição: Conceção, Montagem e Avaliação. São Paulo: Brasil Annablume.

Hooper-Greenhill, Eilean. 1998. Los Museos y Sus Visitantes. Gijón: Ediciones Trea.

IBRAM (Instituto Brasileiro de Museus). 2012. Relatório Final da Pesquisa - O "Não Público" dos Museus: Levantamento Estatístico sobre o "Não-ir" a Museus no Distrito Federal. Brasília: Coordenação de Pesquisa e Inovação Museal do Departamento de Processos Museais do IBRAM. http:// www.museus.gov.br/wp-content/uploads/2013/09/naopublico.pdf

Kirchberg, Volker. 1996. "Museum Visitors and Non-visitors in Germany: A Representative Survey." Poetics: Journal of Empirical Research on Literature, Media and Arts (24): 239-258.

Lang, Caroline, John Reeve, e Vicky Woollard, eds. 2006. The Responsive Museum: Working with Audiences in the Twenty-First Century. London: Ashgate.

Leite, Pedro Pereira. 2012. Objetos Biográficos: A Poética da Intersubjetividade em Museologia. Lisboa: Marca D’Agua Editores. 
Lima, Nei Clara, e Custódia Selma Sena. 2006. Lavras e Louvores. Texto de abertura da exposição de longa duração do Museu Antropológico da UFG. Goiás: Museu Antropológico da Universidade Federal de Goiás.

Meneses, Ulpiano Bezerra de. 1994. "Do Teatro da Memória ao Laboratório da História; a Exposição Museológica e o Conhecimento Histórico.” Anais do Museu Paulista 2: 9-42.

Mensch, Peter van. 2011. "Conclusions of the joint COMCOL-CAMOC-ICOM Europe session." Comunicação apresentada na conferência Participative Strategies in Documenting the Present, Berlin. http://www.comcol-icom.org/annual-conference2011/.

Moutinho, Mário. 1994. “A Construção do Objeto Museológico.” Cadernos de Sociomuseologia 4 (4): 7 -59 .

Oliveira, Vânia Dolores Estevam de. 2012. “Ocupe o Museu: O Museu é Seu.” Revista Museu. http:// www.revistamuseu.com.br/18demaio/artigos.asp?id=32847.

Pastor Homs, Maria Immaculada. 2004. Pedagogía Museística: Nuevas Perspetivas y Tendencias Actuales. Barcelona: Ariel.

Peirano, Marisa. 1999. “Antropologia no Brasil (Alteridade Contextualizada).” In O que Ler na Ciência Social Brasileira (1970-1995), organizado por Sérgio Miceli. São Paulo: Editora Sumaré e Associação Nacional de Pós-Graduação e Pesquisa em Ciências Sociais.

Simon, Nina. 2010. The Participatory Museum. Santa Cruz, Califórnia: Museum 2.0. http:// www.participatorymuseum.org/.

Soulier, Virginie. 2013. "Donner la Parole aux Autochtones: Quel est le Potentiel de Reconnaissance de l'Exposition à Plusieurs Points de Vue dans les Musées?” Tese de doutoramento, Université du Québec à Montréal e Université D’Avignon et des Pays de Vaucluse.

Tojal, Amanda Pinto da Fonseca. 2007. "Políticas Públicas Culturais de Inclusão de Públicos Especiais em Museus.” Tese de doutoramento, Escola de Comunicações e Artes, Universidade de São Paulo.

Vasconcellos, Camilo M. 2012. "Museus Antropológicos e Universitários: Por um Novo Diálogo Junto ao Público." In Questões Indígenas e Museus: Debates e Possibilidades. Coleção Museu Aberto. Coordenado por Marília Xavier Cury, Camilo de Mello e Ortiz Vasconcellos e Joana Montero, 129136. Brodowski: ACAM Portinari; Museu de Arqueologia e Etnologia da Universidade de São Paulo: Secretaria de Estado da Cultura.

Velho, Gilberto. 2003. Projeto e Metamorfose: Antropologia das Sociedades Complexas. Rio de Janeiro: Jorge Zahar Editor.

\section{NOTAS}

1. A importância da individualidade e da subjetividade na construção da memória, de uma ótica antropológica, pode ser vista em Velho (2003). Desse ponto de vista, as narrativas constitutivas da memória são não-lineares, incompletas, fragmentárias.

2. Sobre políticas públicas para inclusão e os programas educativos para públicos especiais em museus ver Tojal (2007) e sobre a inclusão social em museus ver Aidar (2002), entre outros.

3. Trata-se de uma reserva indígena criada em 1961, situada no Centro-Oeste do Brasil. Agrega inúmeras etnias, entre elas: Yawalapiti, Kalapalo, Kuikuro, Aweti, Kamaiurá, Suyá, Waura, Ikpeng, Trumai, Mehinako. 
4. A Semana de Museus é uma programação nacional instituída pelo Instituto Brasileiro de Museus (IBRAM), desde 2002, e integra inúmeras atividades realizadas por museus em todo o território brasileiro.

5. O conceito de não-público ou não-visitantes de museus é adotado entre autores de diversos países. Kirchberg apresentou uma pesquisa sobre a Alemanha, em 1996. No Brasil, uma pesquisa com este perfil realizada pelo IBRAM (2012) identificou que 76,67 \% dos 1200 entrevistados no distrito federal não visitam museus.

6. Le maison en petit cubes, título da curta-metragem japonesa, criado por Kunio Kato em 2008. 0 filme foi escolhido como agente provocador e gerou depoimentos significativos sobre as memórias dos participantes entrelaçadas com espaços e tempos da cidade de Goiânia.

7. A previsão de permanência da exposição à visitação pública era até o final do mês de setembro daquele ano, mas uma greve geral dos servidores técnico-administrativos das instituições de ensino superior brasileiras obrigou o fechamento da exposição no início do movimento grevista no dia 13 de junho de 2012.

8. Trata-se de programas de ensino especial que tem por objetivo universalizar a alfabetização de jovens e adultos brasileiros que não tiveram acesso à educação formal na infância.

9. Veja-se http://partizipatives-museum.de/

10. Outras referências relevantes são Black (2005) e Lang, Reeve e Woollard (2006).

11. Em recente palestra no MA, Tendências Contemporâneas da Museologia na Europa, ocorrida a 19 de agosto de 2013, Mensch retomou este debate e afirmou a necessidade de os museus pensarem a participação não somente em exposições, mas também em outras etapas e áreas do seu fazer.

\section{RESUMOS}

Este texto visa contribuir com a reflexão sobre conteúdos biográficos de curadoria, especialmente no que se refere às biografias do público como conteúdo, por meio do relato e análise de uma experiência de participação biográfica no Museu Antropológico da Universidade Federal de Goiás, na cidade de Goiânia (Brasil). Trata-se da exposição Ocupe o Museu, cujas atividades se basearam metodologicamente nas pedagogias inclusivas que, entre outras ações, procuraram alcançar o não-público do museu e transformá-lo em produtor de conteúdos museológicos. A exposição contou com o empréstimo e doação de objetos, fotografias, narrativas orais e fílmicas de moradores do entorno do museu. Mais do que a integração de acervo desse segmento da população, as experiências de participação biográfica tiveram lugar nas inúmeras reuniões de preparação e montagem da exposição e nas rodas de conversas que sucederam a abertura da exposição em duas ocasiões especiais. Também serão analisados os desdobramentos da ideiamotor Ocupe o Museu em outras atividades desenvolvidas nos últimos dois anos.

This paper aims to reflect on biographical content curation, namely biographies of the public as content, by reporting and analyzing an experience of biographic participation in the Anthropological Museum of the Federal University of Goiás, in the city of Goiânia, Brazil. The exhibition Occupy Museum whose activities were methodologically based on inclusive pedagogies sought to reach out to the museum's non-publics and to transform them into roducers of museological contents. The exhibition featured loans and gifts of objects, photographs and oral and film narratives by residents of the area surrounding the Museum. More than integration of collections belonging to this populations segment, experiences of biographical participation were 
developed in numerous meetings for the preparation of the exhibition and in the conversation rounds that followed the opening of the exhibition on two special occasions. The application of the idea-motor of Occupy Museum into other activities in the last two years is also analyzed.

ÍNDICE

Keywords: museum public, exhibition, social empowerment, participation, Anthropological Museum Federal University Goiás

Palavras-chave: Participação, públicos, exposição, valorização social, Museu Antropológico Universidade Federal Goiás

\section{AUTORES}

\section{MANUELINA MARIA DUARTE CÂNDIDO}

Doutora em Museologia pela Universidade Lusófona de Humanidades e Tecnologias de Lisboa (Portugal). É professora do curso de bacharelado em Museologia da Universidade Federal de Goiás (Brasil). As suas áreas de atuação são as seguintes: teoria e gestão museológica, musealização da arqueologia, património cultural, museus, e educação não-formal. manuelin@uol.com.br

\section{NEI CLARA DE LIMA}

Doutora em Antropologia Social pela Universidade Nacional de Brasília (Brasil). É professora aposentada da Universidade Federal de Goiás e diretora do Museu Antropológico da mesma universidade. Atua nas seguintes áreas: teoria antropológica, oralidade, património cultural imaterial, memória e museus.neiclara@gmail.com 